\title{
EFEKTIVITAS MEDIASI DALAM PENYELESAIAN SENGKETA PERDATA DI PENGADILAN NEGERI LUBUK PAKAM KELAS IA
}

\author{
Oleh: \\ Nanci Yosepin Simbolon \\ Nancy Saragih \\ Universitas Darma Agung, Medan \\ E-mail: \\ nancisimbolon123@gmail.com \\ nancysaragihgaringging12@gmail.com
}

\begin{abstract}
Mediation is an obligation that must be taken by disputing parties who wish to resolve disputes in court. The existence of mediation in civil dispute resolution in court is regulated in the Regulation of the Supreme Court of the Republic of Indonesia Number 1 of 2016 concerning Mediation Procedures in Courts which contains ten principles consisting of obligatory mediation, autonomy of the parties, mediation in good faith, time efficiency, mediator certification, the mediator's responsibility, confidentiality, financing, repetition of mediation, outof-court peace agreements that are an integral part in resolving disputes in court. The method used in this discussion is a juridical empirical research method using a qualitative approach. The results of this study indicate that the effectiveness and application of PERMA No.1 of 2016 at the Lubuk Pakam District Court has been carried out well as stipulated in the regulation. The application of PERMA 2016 at the Lubuk Pakam District Court is not effective. The effectiveness of PERMA at the Lubuk Pakam District Court is still very low, reaching only $4.58 \%$ in 2018 and $3.65 \%$ in 2019. Achievement with successful cases in mediation depends on the respective parties. Obstacles or constraints from the mediation regulation are from the parties and the absence of advocate support.
\end{abstract}

\section{Keywords: Effectiveness of Mediation, Perma No.1 Year 2016, Good Faith}

\section{ABSTRAK}

Mediasi merupakan kewajiban yang harus ditempuh oleh para pihak bersengketa yang ingin menyelesaikan sengketa di Pengadilan. Eksistensi mediasi dalam penyelesaian sengketa perdata di pengadilan diatur dalam Peraturan Mahkamah Agung Republik Indonesia Nomor 1 Tahun 2016 Tentang Prosedur Mediasi di Pengadilan yang memuat sepuluh prinsip yang terdiri dari mediasi wajib ditempuh, otonomi para pihak, mediasi dengan itikad baik, efisiensi waktu, sertifikasi mediator, tanggung jawab mediator, kerahasiaan, pembiayaan, pengulangan mediasi, kesepakatan perdamaian di luar pengadilan yang menjadi bagian dalam integral dalam penyelesaian sengketa di pengadilan. Metode yang digunakan dalam pembahasan tersebut adalah metode penelitian yuridis empiris dengan menggunakan pendekatan kualitatif. Hasil penelitian ini menunjukkan 
bahwa efektivitas serta penerapan PERMA No.1 Tahun 2016 di Pengadilan Negeri Lubuk Pakam telah terlaksana dengan baik sebagaimana telah diatur dalam peraturan tersebut. Penerapan PERMA 2016 di Pengadilan Negeri Lubuk Pakam memang kurang efektif. Keefektifan PERMA di Pengadilan Negeri Lubuk Pakam masih sangat rendah hanya mencapai $4,58 \%$ di tahun 2018 dan 3,65\% di tahun 2019. Pencapaian dengan perkara berhasil di mediasi itu tergantung kepada para pihak masing-masing Hambatan atau kendala dari peraturan mediasi tersebut yaitu dari para pihak dan tidak adanya dukungan advokat.

\section{Keywords: Efektivitas Mediasi, Perma No.1 Tahun 2016, Itikad Baik}

\section{PENDAHULUAN}

Sengketa ialah suatu perselisihan yang terjadi antara dua pihak/lebih yang saling mempertahankan persepsinya masing-masing dimana perselisihan tersebut dapat terjadi karena adanya suatu wanprestasi dari pihak-pihak atau salah satu pihak dalam perjanjian.Sengketa biasanya bermula dari suatu situasi di mana ada pihak yang merasa dirugikan oleh pihak lain.Pihak yang merasa dirugikan akan menyampaikan ketidak puasannya kepada pihak kedua.

Apabila pihak kedua dapat menanggapi dan memuaskan pihak pertama, selesailah konflik tersebut, sebaliknya jika reaksi pihak kedua menunjukkan perbedaan pendapat atau memiliki nilai-nilai yang berbeda, akan terjadilah apa yang dinamakan sengketa. Mediasi dapat diintensifkan dengan cara menggabungkan proses mediasi kedalam prosedur berperkara di Pengadilan Negeri.Proses mediasi di pengadilan menjadi bagaian hukum acara perdata yang dapat memperkuat dan mengoptimalkan fungsi lembaga peradilan dalam penyelesaian sengketa perdata di Pengadilan Negeri.

Reformasi birokrasi Mahkamah Agung Republik Indonesia yang berorientasi pada visi terwujudnya badan peradilan Indonesia yang agung,sesuai dengan tugas pokok pengadilan yang bersifat memeriksa dan memutus/ajudikatif.Mahkamah Agung mengeluarkan Peraturan Mahkamah Agung (PERMA) No.1 Tahun 2016, sebagai upaya mempercepat,mempermudah dan mempermurah proses penyelesaian sengketa di Indonesia.Mediasi memberikan akses yang lebih besar kepada pencari keadilan dengan melihat itikad baik para pihak untuk menghadiri mediasi yang diharapkan mampu untuk mengotimalkan efektivitas mediasi.

Mediasi merupakan instrument efektif untuk mengatasi penumpukan perkara di pengadilan dan memaksimalkan fungsi lembaga pengadilan dalam penyelesaian sengketa serta mewujudkan peradilan yang sederhana, cepat,berbiaya ringan.Mediasi dimasukkan ke dalam proses peradilan formal melalui PERMA No.1 Tahun 2016.Semua perkara perdata wajib terlebih dahulu diupayakan penyelesaian melalui mediasi sebagaimna dalam pasal 4 ayat (1) PERMA No.1 Tahun 2016. Berdasarkan latar belakang yang telah diurai diatas,penulis tertarik untuk menyusun skripsi dengan judul "Efektivitas Mediasi Dalam Penyelesaian Sengketa Perdata di Pengadilan Negeri Lubuk 
Pakam."Hal ini penting agar dapat diketahui bagaimana proses penyelesaian sengketa perdata dengan mediasi sesuai PERMA No.1 Tahun 2016,mediator dan pelaksana mediasi,hambatan dan upaya untuk mengoptimalkan pelaksanaan mediasi di Pengadilan Negeri,Aturan tentang itikad baik sesuai Perma No.1 Tahun 2016 agar menjadikan mediasi menjadi pilihan dalam penyelesaian sengketa perdata.

\section{TINJAUAN PUSTAKA}

Mekanisme penyelesaian sengketa di atur dalam sistem Hukum Negara ataupun secara tradisional telah menjadi sistem yang dipakai dalam kelompok masyarakat.

i. Penyelesaian Di Dalam Pengadilan (Litigasi)

Litigasi adalah proses gugatan atas suatu sengketa yang di ritualisasikan untuk menggantikan konflik sesungguhnya, dimana para pihak memberikan kepada seorang pengambil keputusan (Hakim) atas dua pilihan yang bertentangan. Litigasi merupakan proses menyelesaikan perselisihan hukum di pengadilan di mana setiap pihak yang bersengketa mendapatkan kesempatan untuk mengajukan gugatan dan bantahan.Pasal 6 ayat (1)Undang-Undang Nomor 30 Tahun 1999 tentang Arbitrase dan Alternatif Penyelesaian Sengketa ("UU Arbitrase dan APS") berbunyi:

"Sengketa atau beda pendapat perdata dapat diselesaikan oleh para pihak melalui alternatif penyelesaian sengketa yang didasarkan pada itikad baik dengan mengesampingkan penyelesaian secara litigasi di Pengadilan Negeri."
Litigasi bersifat formal terkait dengan hukum acara,para pihak saling beragumentasi,mengajukan alat bukti,pihak ketiga (hakim) tidak ditentukam oleh pihak dan keahliannya bersifat umum,prosesnya bersifat terbuka dan transparan serta hasil akhirnya berupa putusan yang didukung pandangan atau pertimbangan hakim.Kelemahan dari proses penyelesaian sengketa secara litigasi adalah proses yang berlangsung lama dan berlarut-larut. Untuk mendapat putusan akhir yang mengikat, menimbulkan ketegangan antar para pihak yang bersengketa, kemampuan pengetahuan hukum bersifat umum, tidak bersifat rahasia. Kelebihan litigasi adalah proses beracara jelas dan ada protapnya.

ii. Penyelesaian Di Luar Pengadilan (Non Litigasi)

Alternative dispute resolution(ADR) atau alternatif penyelesaian sengketa (APS) merupakan upaya penyelesaian sengketa di luar litigasi (non litigasi).

\section{METODE PELAKSANAAN}

Penelitian ini menggunakan metode penelitian yuridis empiris. Penelitian yuridis empiris merupakan istilah lain yang digunakan dalam penelitian hukum sosiologis, dan dapat pula disebut pula dengan penelitian lapangan. Karena penulis terjun langsung ke lokasi penelitian untuk mencari data primer melalui penelitian lapangan baik melalui pengamatan (observasi) ataupun wawancara untuk menganalisa keefektifan suatu hukum.Penelitian jenis empiris ini terdiri dari penelitian terhadap identifikasi hukum dan efektivitas hukum. 
4. HASIL DAN PEMBAHASAN

A. Penerapan Prosedur Mediasi Dalam Penyelesaian Sengketa Perdata Di Pengadilan Negeri Lubuk Pakam Kelas Ia

Prosedur mediasi di pengadilan dilakukan secara rahasia atau tertutup. Pemilihan tempat pelaksanaan mediasi sebagai proses mediasi di pengadilan berdasarkan kesepakatan bersama diantara para pihak yang bersengketa. Ada beberapa tahapan mediasi secara umum yaitu :

1. Tahap Pendahuluan

Dimulai dengan konsultasi dengan para pihak tentang tempat dan waktu mediasi,identitas pihak yang hadir,aturan tempat duduk dan sebagainya.

2. Sambutan mediator

Dalam hal ini mediator menguraikan urutan kejadian, meyakinkan para pihak yang masih ragu, menerangkan peran mediator dan para pihak, menegaskan bahwa para pihak yang bersengketalah "berwenang" untuk mengambil keputusan, menyusun aturan dasar dalam menjalankan tahapan, memberikan kesempatan mediator untuk membangun kepercayaan dan menunjukkan kendali atas proses, mengkonfirmasi komitmen para pihak terhadap proses.

3. Presentasi para pihak

Setiap pihak diberi kesempatan untuk menjalankan permasalahannya kepada mediator secara bergantian, tujuan dari presentasi ini adalah untuk memberikan kesempatan kepada para pihak untuk mendengar sejak dini, dan juga memberi kesempatan setiap pihak mendengarkan permasalahan dari pihak lainnya secara langsung.

4. Identifikasi hal-hal yang sudah disepakati
Salah satu peran yang penting bagi mediator adalah mengidentifikasi hal-hal yang telah disepakati antara para pihak sebagai landasan untuk menjalankan proses negosiasi.

5. Mendefenisikan dan mengurutkan permasalahan

Mediator perlu membuat suatu 'struktur" dalam pertemuan mediasi yang meliputi masalah-masalah yang sedang diperselisihkan dan sedang berkembang. Dikonsultasikan dengan para pihak, sehingga tersusun “ daftar permasalahan" menjadi suatu agenda.

6. Negosiasi dan pembuatan keputusan

7. Pertemuan terpisah

Untuk menggali permasalahan yang belum terungkap dan diangap penting guna tercapainya kesepakatan, untuk memberikan suasana dinamis pada proses negosiasi bilaman jalan buntu, menjalankan tes realitas terhadap para pihal, untuk menghindarkan kecenderungan mempertahankan pendapat para pihak pada joint sessions,untuk meningkatkan kembaali atas hal-hal yang dicapai dalam proses ini dan mempertimbangkan akibat bila tidak tercapai kesepakatan.

8. Pembuatan keputusan akhir Para pihak dikumpulkan kembali guna mengadakan negosiasi akhir,dan menyelesaikan beberapa hal dengan rinci, mediator berperan untuk memastikan bahwa seluruh permasalahan telah dibahas, dimana para pihak merasa puas dengan hasil akhir.

9. Mencatat keputusan

Pada kebanyakan mediasi, perjanjian akan dituangkan ke dalam tulisannya,dan ini bahkan menjadi suatu persyaratan dalam kontrak mediasi. 
10. Kata penutup

Mediator biasanya memberikan ucapan penutup sebelum mengakhiri mediasi.

\section{B. Kendala Dan Hambatan Dalam Penerapan Proses Mediasi Di Pengadilan Negeri Lubuk Pakam Kelas Ia}

1. Faktor penegak hukum

a. Dari Para Hakim (Mediator Hakim)

a. Mediator bersikap pesimis dengan maksud dan tujuan mediasi di pengadilan untuk mengurangi penumpukan perkara di pengadilan.

b. Rendahnya motivasi mediator dari hakim. Banyak hakim di pengadilan tingkat pertama sebagai ujung tombak pelaksanaan mediasi tidak sepenuh hati menyelesaikan sengketa yang dihadapinya secara damai Hal tersebut dilakukan karena mereka merasa hanya mendapat sedikit manfaat atau bahkan tidak sama sekali.

c. Sulitnya mengatur waktu (scheduling) antara mediator, dan para pihak. Jika para pihaknya dalam jumlah yang banyak dan domisilnya berjauhan ( di luar kota)

d. Tergantung kepada masingmasing mediatornya aktif atau tidak dalam mediasi. Ada yang komitmen terhadap tujuan adanya mediasi yaitu mengurangi penumpukan perkara, ada yang merasa dibebani dengan adanya prosedur mediasi ini yaitu menambah beban kerja.

e. Anggapan bahwa mediasi yang gagal menambahi beban kerja pengadilan. f. Belum adanya pengaturan yang rinci mengenai insentif bagi hakim yang berhasil menjalankan fungsi mediatornya.

\section{b. Dari Para Advokat}

Dalam hal melakukan mediasi, banyak kuasa hukum yang merasa kurang yakin terhadap efektivitas dari mediasi, terutama pada segi kekuatan eksekusi kesepakatan yang dicapai nantinya. Selain itu kuasa hukum terbiasa dengan pola pikir litigasi, apalagi jika posisinya kuat, kemengangan dapat dicapai melalui litigasi walaupun mungkin akan memakan waktu yang lama tetapi akan lebih pasti apabila dijatuhkan dengan putusan akhir.

c. Dari Para Pihak

Pada dasarnya mediasi di Pengadilan merupakan kewajiban untuk diikuti oleh para pihak yang berperkara. Tidak mengikuti proses mediasi, maka putusan akan batal demi hukum. Oleh sebab itu, para pihak menganggap bahwa mediasi hanyalah prosedur yang bersifat formalitas belaka, sehingga banyak pihak enggan untuk berdamai pada saat mediasi. Kesulitan saat melakukan perdamaian oleh para pihak di Pengadilan Negeri maupun Mahkamah Agung, sebenarnya dilatar belakangi adanya faktor gengsi belaka. Para pihak yang berperkara enggan untuk memulai suatu perdamaian, karena didasari oleh ego para pihak masing-masing. Belum lagi apabila para pihak yang berperkara selalu merasa memiliki atas obyek sengketa, terlebih untuk kasus sengketa tanah.

\section{KESIMPULAN}

Berdasarkan hasil kajian yang telah dijabarkan oleh penulis pada bab-bab sebelumnya, maka 
penulis memberikan kesimpulan sebagai berikut :

1) Penerapan proses mediasi di Pengadilan Negeri Lubuk Pakam secara umum telah berjalan sesuai prosedur yang berlaku yaitu Peraturan Mahkamah Agung Nomor 1 Tahun 2016 tentang Prosedur Mediasi di Pengadilan. Dalam praktiknya semua perkara yang masuk ke pengadilan negeri Lubuk Pakan akan dimediasi terlebih dahulu dan apabila perkara tidak di mediasi maka putusan dianggap batal demi hukum. Keberadaan Perma Nomor 1 Tahun 2016 ini masih belum efektif penerapannya di Pengadilan Negeri Lubuk Pakam, karena volume perkara yang diajukan di Pengadilan Negeri Lubuk Pakam sangatlah banyak terlebih lagi mediator yang tersedia di Pengadilan Negeri Lubuk Pakan hanyalah mediator hakim sedangkan seorang hakim mempunyai tugas yang banyak dalam memeriksa, mengadili, dan memutus berbagai penumpukan perkara yang telah diajukan di Pengadilan Negeri Lubuk Pakam.

2) Kendala yang dialami mediator dalam pelaksanaan mediasi dapat dilihat dari para pihak, dimana jika para pihak tidak mempunyai itikad baik maka akan mempersulit mediator dalam mencari dan menemukan solusi yang tepat untuk menyelesaikan proses mediasi. Bahwa mediasi itu hanya akan efektif jika para pihak benarbenar ingin menyelesaikan sengketa mereka dengan cara mediasi. Jika hanya satu pihak saja yang mempunyai itikad baik maka mediasi tidak akan berhasil. Salah satu hal yang juga menjadi penyebab tidak berhasilnya mediasi ini adalah pemahaman masyarakat mengenai keberadaan mediasi. Seharusnya mediasi dapat disebarluaskan atau disosialisasikan dengan baik agar measyarakat mengetahui betapa pentingnya medisi dalam menyelesaikan sengketa.

\section{DAFTAR PUSTAKA}

\section{A. BUKU-BUKU :}

Abbas, Syahrizal, Mediasi : Dalam Hukum Syariah, Hukum Adat dan Hukum Nasional. Jakarta: Kencana, 2009.

Abdulkadir, Muhammad, Hukum Acara Perdata Indonesia, Bandung : PT Citra Aditya Bakti, 2008.

Astarini, Dwi Rezeki Sri, Mediasi Pengadilan Salah Satu Bentuk Penyelesaian

Sengketa Berdasarkan Asas Peradilan CEPAT, Sederhana dan Biaya Ringan, Bandung: Alumni, 2013

Bagir,Mannan, Mediasi Sebagai Alternatif Menyelesaikan Sengketa dalam Varia Peradilan No.248 Juli 2006 .

Denaldy, Mauna, Mediator's Skill dalam Mahkamah Agung RI Mediasi dan Perdamaian, 2003.

Diah Sulastri,Dewi, Kode Etik dan Pedoman Perilaku Mediator. Disampaikan di 
$\begin{array}{lrr}\text { Kuliah Umum } & \text { Mediasi, } \\ \text { Badan Litbang } & \text { Diklat } \\ \text { Mahkamah Agung } & \text { RI,Mega } \\ \text { Mendung,2015 } & \end{array}$ Emerzon, Joni, Alternatif Penyelesaian Sengketa di Luar Pengadilan : Negosiasi, Mediasi, Konsiliasi dan Arbitraes, Jakarta: Gramedia Pustaka Utama,2002

Frans Hendra,Winata, Hukum Penyelesaian Sengketa Arbitrase Nasional Indonesia dan Internasional, Jakarta:Sinar Grafika.

Gunawan Widjaja, Seri Hukum Bisnis : Aternatif Penyelesaian Sengketa, Jakarta :PT Raja Grafindo Persada, 2002.

Goodpaster, Gerry, Negosiasi dan Mediasi : Sebuah Pedoman Negosiasi dan Penyelesaian Sengketa melalui Negosiasi, Jakarta : ELIPS Project,1993

Harlien Budiono, Ajaran Umum Hukum Perjanjian dan Penerapannya di Bidang Kenotariatan, Bandung: Citra Aditya.

Mertokusumo, Sudikno, Hukum Acara Perdata Indonesia, Yogyakarta : Liberty,1988

\section{B. PERATURAN PERUNDANG-}

\section{UNDANGAN}

Peraturan Mahkamah Agung No.1

$\begin{array}{lcr}\text { Tahun } & 2016 \quad \text { Tentang } \\ \text { Prosedur } & \text { Mediasi } & \text { di } \\ \text { Pengadilan } & & \end{array}$

\begin{tabular}{|c|c|c|c|}
\hline \\
\hline \multirow{2}{*}{\multicolumn{4}{|c|}{$\begin{array}{c}\text { Undang-Undang Dasar } \\
\text { Republik Indonesia } \\
1945 \text { Undang- }\end{array}$}} \\
\hline & & & \\
\hline \multirow[t]{4}{*}{ Kitab } & \multicolumn{3}{|c|}{ Undang-Undang } \\
\hline & \multirow{2}{*}{\multicolumn{3}{|c|}{$\begin{array}{l}\text { Perdata HIR (Herz } \\
\text { Inlandsch Reglement) dan }\end{array}$}} \\
\hline & & & \\
\hline & \multicolumn{3}{|c|}{$\begin{array}{l}\text { RBG (Rechtreglement voor } \\
\text { de Buitengewesten) }\end{array}$} \\
\hline \multicolumn{3}{|c|}{ Peraturan } & Agung \\
\hline \multicolumn{2}{|r|}{ Nomor } & Tahun & 2016 \\
\hline \multicolumn{4}{|c|}{$\begin{array}{l}\text { Tentang Prosedur Mediasi } \\
\text { Di Pengadilan }\end{array}$} \\
\hline
\end{tabular}

Undang-Undang Dasar Negara Republik Indonesia Tahun 945 Undang-

Perdata HIR (Herzien

Inland sch Reglement) dan

RBG (Rechtreglement voor

Nomor 1 Tahun 2016

Di Pengadilan 